\title{
SYNTHESIS, CHARACTERISATION AND APPLICATION OF NEW LOW-COST COMPOSITE ION EXCHANGERS
}

\section{G. SENTHIL KUMAR \& R. BASKARAN}

Department of Chemistry, Annamalai University, Annamalainagar, Chidambaram, Tamilnadu, India

\begin{abstract}
This article represents a simple method for preparing and characterising of low cost ion exchangers of sulphonated carbon prepared from Tribulus Terrestris Linn., (Family-Zygophyllaceae) - as a source of cheap plant material blended with phenol-formaldehyde as a cross - linking agent.

All the important physico-chemical, thermal and spectral properties of the ion exchangers have been determined. The synthesised resins having a cation exchange capacity upto 1.96 m.mol.g ${ }^{-1}$.

KEYWORDS: Synthesis, Phenol Formaldehyde Resin, Composites, Blending, Swelling, FT-IR-TGA, Selectivity \& Waste
\end{abstract}

Received: Jun 05, 2020; Accepted: Jun 25, 2020; Published: Jul 30, 2020; Paper Id.: IJMPERDJUN2020525

\section{INTRODUCTION}

The ion exchange process is a relatively ancient discovery, which allows us to remove undesirable ions and replace them with less objectionable ions, like $\mathrm{H}^{+}, \mathrm{Na}^{+}$and $\mathrm{OH}^{-}, \mathrm{Cl}^{-}$ions. The process and commercial application for ion exchange are less than 100 years old ${ }^{1}$. The modern ion exchange resins (IERs) used to-day for water and wastewater treatment is about 50 years old. Although one can discover new ways to use these resins, the basic chemistry has not changed in a half-a-century ${ }^{2}$.

The first synthetic cation exchange resin was obtained by Adams and Holmes ${ }^{3}$. It was shown that strongly acidic groups $\left(-\mathrm{SO}_{3}^{-} \mathrm{H}^{+}\right)$may be introduced either by sulphonation or by substitution of phenol sulphonic acid for phenol. The resultant resin could be used as IER at acidic pH value. The IER could be used in the hydrogen form.

Many investigators have introduced composite resin which is used as an IER. Phenolic resin, sulphonated phenol - formaldehyde, sulphonated polystyrene - divinyl benzene, and polyacrylonitrile are the major organic binding matrices which are used for preparing such composite resins ${ }^{4,5}$.

Many ion-exchangers owe their origin to petroleum products and there is a continual increase in their cost. Hence, there is a timely need to synthesise low cost ion exchange resins (IERs) and lower the cost of IERs by blending it with sulphonated carbons prepared from plant materials. Earlier reports available in literature revealed that the cheaper composite ion-exchangers could be prepared by partially blending the phenol-formaldehyde matrices with sulphonated carbons from coal $^{6}$, saw dust ${ }^{7}$, spent $\operatorname{coffee}^{8}$, cashew nut husk ${ }^{9}$, wheat husk ${ }^{10}$, turmeric plant $^{11}$, spent tea, gum tree bark ${ }^{12}$, Accacia nilotica ${ }^{13}$, and Egyptian bagasse pith $^{14}$.

Ion exchange process is suitable in the treatment of wastewater containing metal ions discharged from plating and other industries ${ }^{15}, 16$. Also, it is a convenient way to concentrate and remove the ions of valuable metals like, copper, zinc and chromium. Special process using selective IERs are also available in the recovery of 
precisious nobel metals like gold, platinum and silver ${ }^{17}$.

The present study is aimed at to synthesise and charactersise new composite ion exchangers of $\mathrm{PhOH}-\mathrm{HCHO}$ type, blended with Sulphonated Tribulus Terrestris - Linn Carbon (STTC) and to determine the column / cation exchange capacity (CEC) or ion exchange capacity (IEC) for some selective metal ions.

\section{EXPERIMENTAL}

\section{Materials}

Phenol and formaldehyde used in the present study were of Fischer reagents (India). LR grade of con. sulphuric acid (Sp.gr. $=1.82$ ) was used. Tribulus Terrestris - Linn., (family- Zygophyllaceae) plant materials especially fruits were locally collected and cleaned before use.

\section{Methods}

Tribulus Terrestris: Linn.,., thorn (500g) were cut into small pieces, then carbonised and sulphonated by con. sulphuric acid $(500 \mathrm{ml})$ and kept at room temperature $\left(30 \pm 1^{\circ} \mathrm{C}\right)$ for $24 \mathrm{~h}$ and heated at $90^{\circ} \mathrm{C}$ in a hot air-oven for 6 hours. It was then cooled, washed with distilled water several times and finally with double distilled (DD) water in order to remove excess free acid and dried at $70^{\circ} \mathrm{C}$ for $12 \mathrm{~h}$. It was labeled as STCC.

The phenol formaldehyde resin (PFR) and the composites containing various percentage $(w / w)$ of sulphonated Tribulus Terrestris - Linn.,., carbon (STTC) in the total blend as $0,10,20,30,40$ and $50(w / w)$, respectively were prepared 7, $10-13$ and labeled as PFR, TT1, TT2, TT3, TT4 and TT5. These resin and composites were sieved into 210 - 300 micron (Jayant sieve, India) for further charcterisation. The various physico - chemical properties like absolute density - dry (toluene medium) and wet (water medium), percentage of gravimetric swelling percentage of attritional breaking and CEC were determined as per the literature methods ${ }^{7,10,12,17,18}$. The cation exchange capacity (CEC) and the regeneration level was studied with brine $(\mathrm{NaCl})$ solutions following the method reported in literature ${ }^{19-24}$.

\section{Instrumental Studies}

The FT-IR spectral data of pure resin (PFR), 30\% (w/w) composite and pure sulphonated Tribulus Terrestris Linn.,carbon (STTC) were recorded with a JASCO FT-IR 460 plus FT-IR spectrometer by using KBr pellets. To establish the thermal degradation of the samples, TGA and DTA traces were obtained for phenol - formaldehyde resin (PFR) and $30 \%(w / w)$ composite resin by using TZSCH- Geratebau GmbH Thermal analysis. The surface morphologies of synthesized IERs were studied using a scanning electron microscope (SEM, JEOLJSM 6390).

\section{RESULTS AND DISCUSSIONS}

The data given in Table 1 reveal that the experimental and theoretical composition of STTC in the composites (TT1 - TT5) are in good agreement with each other. The results are similar to those obtained by Sharma et $\mathrm{l}^{6}$. This indicate that the methods adopted for the synthesis of PFR and composites (TT1 - TT5) are more reliable and reproducible.

The data given in Table 2 and show that the absolute density values in both hydrated and dehydrated states decrease steadily from pure resin to $50 \%$ of $(w / w)$ STTC in composite resin and then finally to pure STTC. This indicates that PFR and the composites (TT1 - TT5) are more closely packed ${ }^{7-14}$. It is found that the absolute density of $100 \%$ STTC possess only $48.58 \%$ and $43.56 \%$ of density of PFR in hydrate (wet) and dehydrate (dry) states, respectively. This result 
indicates that STTC also has closely packed structure ${ }^{17,18}$.

The value of absolute density of composite resin in dry and wet form depends upon the structure of resin and its degree of cross linking and ionic form ${ }^{25-27}$. Hence, the high density values are obtained for the composite resins. The values of density ( both wet and dry densities) presented in Table 2 indicate the high degree of cross linking, and hence the composite resins are suitable for making columns for treating polar and non - polar effluent liquids. Moreover, the wet and dry density values are close to each other, which indicate that the samples may be macro porous in nature. From the data, it is clear that there is no considerable decrease in absolute density in both hydrated and dehydrated states up to 30\% blending of PFR with STTC in the condensates, indicating that they also have closely packed structures with high degree of cross-linking and hence could be more suitable for making ion exchange columns for polar and non-polar liquids of high density $22-24$.

The data given in Table 2 indicate that the percentage of swelling decreases from PFR (87.42\%) to STTC (39.37\%). It indicates that, the values for pure resin, and composites are not as high as compared to that of the conventional gel type IERs indicating rigidity in the matrix and therefore the pores of condensates are of non-gel type and macroreticular ${ }^{17}$. STTC has a swelling capacity of only $39.90 \%$ as compared to that of PFR. This extremely low value may be due to certain rigidity in their matrix. The blending of PFR with $30 \%(w / w)$ of STTC reduces the gravimetric swelling value as $68.55 \%$ of that of the pure PFR, thus decreasing $20.87 \%$ of percentage of swelling compared to that of the pure PFR. The decrease in $\%$ gravimetric swelling is attributed to the loss of polarity and porosity in condensates. Thus, the condensates may prove to be useful where they are required to stand a high osmotic shock ${ }^{18}$.

The values of attritional breaking presented in Table 2 also represent the stability of the resin, which decrease from pure resin to STTC. Therefore, the mechanical stability is good up to $20 \%(w / w)$ substitution of STTC in pure resin. This observation also shows the possibility of formation of resin in the capillaries of the sulphonated charcoal (STTC) particles $^{10-12}$.

Solubility data indicate the chemical stability of the samples in various solvents. It reveals that PFR, composites and STTC are practically insoluble in almost all the solvents like con. $\mathrm{H}_{2} \mathrm{SO}_{4}, \mathrm{HCl}, \mathrm{HNO}_{3}, \mathrm{CH}_{3} \mathrm{COOH}, \mathrm{CCl}_{3} \mathrm{COOH}$, $\mathrm{CH}_{3} \mathrm{OH}, \mathrm{C}_{2} \mathrm{H}_{5} \mathrm{OH}, \mathrm{CH}_{3} \mathrm{CHO}, \mathrm{CHCl}_{3}, \mathrm{CCl}_{4}, \mathrm{CS}_{2}, \mathrm{C}_{6} \mathrm{H}_{6}$ and $\mathrm{C}_{6} \mathrm{H}_{5} \mathrm{CH}_{3}$, except $20 \%(w / v) \mathrm{NaOH}$ solution. Therefore, it may concluded that $\mathrm{PFR}$, and the composites are having high degree of cross linking in the sample structure i.e., the basic polymeric unit has mostly high molecular weight fractions or atleast the absence of very low molecular weight fractions present in it ${ }^{17,18}$. Hence, they can be used as ion exchangers for treating non-aqueous effluents also ${ }^{13}$. At the same time the samples were partially soluble in $20 \%(w / v) \mathrm{NaOH}$ solution, which indicate the presence of phenolic groups in them. Hence, the industrial effluent having high alkalinity cannot be treated by these ion exchange materials. The insolubility of the resin samples even in the trichloroacetic acid express the rigidity i.e., having high degree of cross linking in them.

Cation / column exchange capacity (CEC) or Ion exchange capacity (IEC) data shown in Table 3 indicate that, the CEC value decreases when the content of STTC $\%(w / w)$ in PFR increases. Fig.1 represents the variations in percentage column capacity for various composites and metal ions.

The relative ion exchange capacity (IEC) of individual metal ions depends upon the atomic radius or number ${ }^{25-29}$. At the same time the CEC also depends upon the anionic part of the metal salt. i.e inter ionic forces of attraction between anions and cations, which plays a vital role in CEC of particular metal salt solution ${ }^{25}$. 26 . On comparing the CEC of 
composites with the CEC values of PFR taking it as 100\% (Fig.1) it is found that 10\% blending of PFR by STTC decreases its CEC to about 10\% (Table 3) blending of PFR by STTC retains CEC values above $90 \%$ for the exchange of $\mathrm{H}^{+}$ions in the $\mathrm{Na}^{+}, \mathrm{K}^{+}, \mathrm{Cu}^{2+}, \mathrm{Ca}^{2+}, \mathrm{Mg}^{2+}, \mathrm{Zn}^{2+}$ and $\mathrm{Pb}^{2+}$ ions. Also it is noted that the composites up to $30 \%$ of STTC retains above $90 \%$ of CEC of PFR for the exchange of $\mathrm{Zn}^{2+}, \mathrm{Pb}^{2+}$ and $\mathrm{Na}^{+}$and retains $80-88 \%$ of CEC for the exchange of $\mathrm{Ca}^{2+}, \mathrm{Cu}^{2+}$, $\mathrm{Mg}^{2+}$ and $\mathrm{K}^{+}$ions (Fig.1). The maximum value of $\%$ of relative ion exchange capacity of composites is for $\mathrm{Zn}^{2+}$ ions and for $\mathrm{Na}^{+}$ions. This is due to the reason that the blending of STTC upto $50 \%(w / w)$ does not affect the value for $\mathrm{Zn}^{2+}$ and $\mathrm{Na}^{+}$ions to a greater extent. Hence, it is more suitable for $\mathrm{Zn}^{2+}$ and $\mathrm{Na}^{+}$ions compared to other ions. However, PFR could be blended up to $30 \%(w / w)$ of STCC and the composites thus obtained would be new and cheap IERs, which could be used for water and wastewater treatment for the removal of metal ions in general. It is useful in industrial applications, especially for the treatment of industrial effluent.

From the CEC data given in Table 3, the cation exchange capacity of the samples for various metal ions was found to decrease in the following order:

\section{$\mathrm{Zn}^{2+}>\mathrm{Na}^{+}>\mathrm{Cu}^{2+}>\mathrm{K}^{+}>\mathrm{Ca}^{2+}>\mathrm{Pb}^{2+}>\mathrm{Mg}^{2+}$}

The order of metal ions based on \% of CEC of metal ions compared with PFR. The selectivity order of metal ions i.e., order of CEC values also depends upon the ionic potential and the hydrated atomic radius of the metal ions in solution

${ }^{26}$. The order of exchange affinities of various metal ions is not unique to ion exchange system. Only under dilute conditions Hofmeister or lyotropic series ${ }^{28}$ is obeyed. But, under high concentration it is different ${ }^{28}$. It is equally important to note that the relative behaviour of these ions for other ionic phenomena deviates the affinity order under the same condition $^{30,31}$. The observed order in the present study is different from that of the Hofmeister or lyotropic series ${ }^{28}$. This may be due to the ionic strength of the metal ions, the internal structure of the polymeric matrix and also due to the selectivity of the metal ions ${ }^{27}$. Finally this indicates that the these composites can partially replace commercial IERs in making the ion exchangers for industrial applications.

In order to test the chemical stability of IER viz., PFR-composites, the samples were boiled with water, benzene and dilute $\mathrm{NaOH}$ for an hour. The CEC of the resulting acid boiled, benzene boiled and alkali boiled samples possess CEC almost similar to the parent/ untreated resins (range 1-2\%). This indicates that these samples are chemically stable(Table 4). In order to test the thermal stability of IER viz., PFR -composites the samples were heated to $100^{\circ} \mathrm{C}$ for an hour. Although the samples lose weight initially on heating, the lost weight is regained after cooling for $24 \mathrm{~h}$, and exposing it to air. This indicates that the IERs are thermally stable upto $100^{\circ} \mathrm{C}$. The CEC values of the thermally treated resins are found to be almost similar to the untreated IER/parent resin within

\section{$1-2 \%$ (Table 4).}

CEC data given in Table 5, indicate that the particle size of $\langle 210 \mu \mathrm{m}$ are fine, $300-500 \mu \mathrm{m}$ and $>500 \mu \mathrm{m}$ are coarse as to cause very low ion exchange capacity compared to $210-300 \mu \mathrm{m}$ particle size. Hence, for the effective IEC, the particle size should be maintained and recommended mesh size is $210-300 \mu \mathrm{m}$. Forty $\mathrm{ml}$ of $0.2 \mathrm{M}$ brine solution $(\mathrm{NaCl})$ effectively regenerates all the composite resin and STCC after the exchange with the $\mathrm{Mg}^{2+}$ ions. Most of the commercial IERs are in $\mathrm{Na}^{+}$form and hence $40 \mathrm{ml}$ of $0.2 \mathrm{M} \mathrm{NaCl}$ could be used as a regenerant for every $2 \mathrm{~g}$ of the resin ${ }^{26}$ (Fig.2).

The IR spectral data are shown in Table 6. It indicates the appearance of absorption band at $1038-1051 \mathrm{~cm}^{-1}(\mathrm{~S}=$ 0 str.) $1152-1192 \mathrm{~cm}^{-1}$ ( $\mathrm{SO}_{2}$ sym str.) and $597-608 \mathrm{~cm}^{-1}$ ( C-S str)- in pure resin (PFR), 30\% composite resin and pure 
STTC(ST3) confirm the presence of sulphonic acid group (Fig.3 )

The appearance of broad absorption band at $3396-3447 \mathrm{~cm}^{-1}$ (bonded -OH str.) indicate the presence of phenolic and sulphonic $-\mathrm{OH}$ group in the samples. The appearance of absorption band at $1603-1639 \mathrm{~cm}^{-1}$ (C-C str.) confirms the presence of aromatic ring in PFR, 30\% blending of STTC in PFR and pure STTC. The absorption band at $1431-1488 \mathrm{~cm}^{-}$

${ }^{1}$ (- $\mathrm{CH}_{2}$.def.) confirms the presence of $-\mathrm{CH}_{2}$ group in the samples. The weak absorption band at $878-888 \mathrm{~cm}^{-1}(-\mathrm{C}-\mathrm{H} \mathrm{def}$.) in samples indicate that the phenols are tetra substituted.

TGA curves shown in Fig.4 revealed that there is a very small (6\%) loss in weight for both PFR, ST3 and STTC upto $80^{\circ} \mathrm{C}$. This is due to the loss of moisture absorbed by resin and STTC. Between $50-190^{\circ} \mathrm{C}$ there is $20 \%$ weight loss in PFR and 15-20\% loss in weight in ST3 and STTC was observed. Upto $450^{\circ} \mathrm{C}$, approximately $57 \%$ loss in weight in PFR and upto $340^{\circ} \mathrm{C}$, approximately $35-42 \%$ weight loss in ST3 and STTC was observed.

In Fig.4, DTA curve shows that two exothermic peaks were obtained in PFR, approximately at $80^{\circ} \mathrm{C}$ and at $466^{\circ} \mathrm{C}$, respectively. At $80^{\circ} \mathrm{C}$, the presence of broad peak was observed, which indicates the dehydration process of resin (PFR). A peak at $466^{\circ} \mathrm{C}$, indicate, the chemical changes of pure resin, which reflect approximately, $57 \%$ weight loss in PFR.

DTA curve of ST3 and STTC (Fig.4) shows that, the same two exothermic peaks were obtained at $99^{\circ} \mathrm{C}$ and at $522^{\circ} \mathrm{C}$, respectively similar to PFR. Again the first broad peak indicates the dehydration of ST3 and STTC and second moderate sharp peak indicates the chemical changes of ST3 and STTC.

From Figs. 4 is concluded that, the limiting temperature for the safer use of PFR and ST3 as ion exchangers was $80^{\circ} \mathrm{C}$, since the resin degrade thermally after $80^{\circ} \mathrm{C}$.

SEM photos of RFR and ST3 and STTC with different magnification (by 100, 500 and 1000 times respectively) are given Fig 5. SEM photos reveal that all these samples are macroporous in nature. The high macroporous carbon obtained from Enicostema axillare form the reservoir in which the resorcinol-formaldehyde sulphonic acid particles are deposited. Hence, the pore diameter decreases in ST3.

\section{CONCLUSIONS}

It is concluded from the present study that PFR sample could be blended with $30 \%(w / w)$ of STTC, without affecting its physico-chemical, thermal properties. Also the effect of particle size and on CEC, its regeneration level by using $\mathrm{NaCl}$, spectral properties and the CEC values of various metal ions of $30 \%(w / w)$ STTC were very close to the original PFR resin. Hence, blending with STTC will definitely lower the cost of IER.

\section{ACKNOWLEDGEMENT}

The authors thank the Management and Principal of their colleges for providing research facilties and constant encouragement, respectively.

\section{REFERENCES}

5. Wachinski A.M, and Etzel J.E. 1997, Environmental ion exchange, Lewis, New York. 16p.

6. Michaud C.F. 1998, Ion Exchange, past, present, future, Technical paper given at water quality association convention. Fort Lauderable, Fla. $28 p$.

7. Kitchener J.A. 1957, Ion Exchange Resins. Wiley New York. 52p 
8. Lento J. etal. 1989, in the proceedings of water management symposium. 18p.

9. Dulanska S, Gardon V, Sebesta F and Matel L. 2015. A rapid determination of 226Ra in water using composite ion exchanger MnO2-PAN. Journal of Radio analytical Nuclear Chemistry, 303: 47-51.

10. Maheshkumar V.. Seenivasanand R. K and Selvapandian P.2016.Synthesis, Characterization and Applications of Phenolformaldehyde Cationic Matrices Blended with Sulphonated Citrus Aurantifolia(L.) Carbon. Journal of Chemical and Pharmaceutical Research, 8(6): 104-111

11. Padma Vasudevan and Sarma N.L.N. 1979.Composite Cation Exchangers. Journal of Applied Polymer Science, 23(5): 14431448 .

12. Paulsamy E. Ayyappan and. Seenivasan R. K.2015. Optimization of Process Parameters for the Removal of Calcium ions by Ion Exchange Process, Journal of Chemical and Pharmaceutical Research, 7(10)::165-173

13. Ragavan D. Girija A..Kathereen B and - Seenivasan R.K. 2014.Synthesis, Characterisation and Application of PhenolFormaldehyde Resin Blended with Sulphonated Terminalia Bellerica, Roxb. Charcoal., International Journal of Research and Development, 3(4): 17-23

14. Subha Devi T. Karpagavalli M and Seenivasan R. K. 2019. Studies on Composites of Resorcinol-Formaldehyde Resin Blended with Sulphonated Aegle Marmelos(L) Correa. International journal of advance in science and Engineering, 8(4): 99-112

15. Kathiresapandian D and Krishnamoorthy S. 1991. Resorcinol-formaldehyde cationic matrices substituted by Curcuma longa charcoal. Indian Journal of.Technology, 29, 487-488.

16. Mariamichel,A and Krishnamoorthy S. 1997.Synthesis and Characterization of New Composite Ion Exchangers. Journal of Scientific and Industrial Research, 56: 680-685.

17. Kannan N, Seenivasan R.K and Mayilmurugan R. 2003. Phenol-Formaldehyde cationic matrices substituted by sulphonated Accasia niotica charcoal Indian Journal of Chemical. Technology, 10: 623-626.

18. Metwally M.S. Metwally N.E and Samy T.M. 1994.Synthesis and studies of Egyptian Bagasse Pith Phenol Formaldehyde Cationic Exchangers. Journal of Applied Polymer Science, 52: 61-67.

19. McGarvey, F and Siber, A. 1985.Removal and Recovery of Metals by Ion Exchange, 23rd Annual Liberty Bell Corrosion Course,.

20. Mc Garvey, F.and Tamaki, D. 1988.Meeting Federal Toxic Metal Regulations with Ion Exchange Resins, $26^{\text {th }}$ Annual Liberty Bell Corrosion Course,

21. Natarajan M and Krishnamoorthy S. 1993.Studies on p-Cresol-formaldehyde cationic resins substituted by coconut shell charcoal. Research and Industry, 38: 278-281.

22. Palanimurugan A and Ragavan D. 2019. Removal of Mono/Divalent metal ions from Cationic Matrices Blended with Sulphonated Cassia Angushfolia VAHAL Carbon for low cost ion exchangers. Indian Journal of Applied Research,,9(2), 65-67

23. Vogel, A.I. 1989.Text Book of Quantitative Chemical Analysis, (Eds. G.H. Bassett, Jeffery, J. Mendham J and Denney R.C. $5^{\text {th }}$ Edn. Longman Groud Ltd., London, pp 186 -192.

24. .Thenmozhi M. Karpagavalli M and.Seenivasan R.K. 2016. Synthesis Characterization and Application of Phenolformaldehyde resin Blended with Sulphonated Sapindus Mukorossi Kaertn carbon. RASAYAN Journal of Chemistry, 9(4): 849 $-857$.

25. Sayee Kannan R. Siva S. Kavitha K and Kannan N.2011. Phenol and Formaldehyde Cationic Resin Blended with Sulphonated 
Aegle Marmelos Charcoal. Material Science Forum, 699:281-291

26. Maheshkumar V.. Seenivasanand R. K and Ananthakumar K.2016. Studies on Ion Exchange Capacity of PhenolFormaldehyde Resin Blended with Sulphonated Tinospora Cordifolia Carbon.Indian Journal of Environmental Protection,36(5): 412-422

27. Yasemin B and Zeki T. 2007. Removal of heavy metals from Aqueous Solution by by Sawdust Adsorption. Journal of Environment Science, 19: 160-166

28. Mahamadi $C$ and Chapeyama R. 2011. Divalent Metal ion removal from Aqueous Solution by Acid-Treated and Garlic Treated Canna Indica Roots.Journal of Applied Science and Environment Mamagement, 15: 97-103

29. Khalid N and Ahmad S. 1999.Removal of Mercury from Aqueous Solution by Adsorption to Rice Husks. Separation Science and Technology, 34(16): 3139-3153.

30. Gupta S and Babu BV.2009.Utilisation of Waste Product ( Tamarind seeds) for the Removal of Cr (IV) from Aqueous Solution: Equiliribrium, Kinetices and Regeneration Studies. Journal of Environment Management, 90: 3013-3022

31. Carland C.E. 1994. Ion Exchange Theory and Practice, Royal Society of Chemistry, K, Chap.4, pp 84-90.

32. Kunin, R. 1958. Ion Exchange Resin, Wiley, Newyork and London, $2^{\text {nd }}$ Edition, Chap.15, pp.320 - 325.

33. Grantham J.G. 982. Ion Exchange Resin, Testing, Duolite International Ltd, 1: Section 14, pp.60 - 68.

34. Diaz D and Mijangos.1987. Metal recovery from hydrometallurgical waste. Journal of Metals,6: 42-44

35. Green B R. 1988.Mechanism of loading of metal cyanides by weak base resin. Reactive Polymers, 8:221-234

\section{ANNEXURES}

Table 1: Amount of reagent used and yield of PFR, condensates (TT1 - TT5) prepared by blending of PFR with various $\%(w / w)$ of STTC

\begin{tabular}{|c|c|c|c|c|c|c|c|}
\hline \multirow[b]{2}{*}{ Sample } & \multirow{2}{*}{$\begin{array}{c}\text { \% of STTC in } \\
\text { IER } \\
\text { (theory) }\end{array}$} & \multicolumn{3}{|c|}{ Amount of reagents used } & \multirow[b]{2}{*}{$\begin{array}{l}\text { STTC } \\
(\mathrm{g})\end{array}$} & \multirow[b]{2}{*}{$\begin{array}{l}\text { Yield } \\
(\mathrm{g})\end{array}$} & \multirow[b]{2}{*}{$\begin{array}{c}\% \text { of STTC in } \\
\text { IER(obs) }\end{array}$} \\
\hline & & $\begin{array}{c}\text { Phenol (g } \\
\text { ) }\end{array}$ & $\begin{array}{c}\text { HCHO } \\
(\mathrm{mL})\end{array}$ & $\begin{array}{c}\text { Con. } \mathrm{H}_{2} \mathrm{SO}_{4} \\
(\mathrm{~mL})\end{array}$ & & & \\
\hline PFR & 0 & 10.0 & 11.5 & 12.5 & 0 & 18.80 & 0 \\
\hline TT1 & 10 & 10.0 & 11.5 & 12.5 & 2.08 & 20.95 & 9.93 \\
\hline TT2 & 20 & 10.0 & 11.5 & 12.5 & 4.70 & 23.98 & 19.60 \\
\hline TT3 & 30 & 10.0 & 11.5 & 12.5 & 8.06 & 27.02 & 29.83 \\
\hline TT4 & 40 & 10.0 & 11.5 & 12.5 & 12.53 & 30.88 & 40.58 \\
\hline TT5 & 50 & 10.0 & 11.5 & 12.5 & 18.8 & 37.14 & 50.62 \\
\hline STTC & 100 & - & - & - & - & - & 100.00 \\
\hline
\end{tabular}

Table 2: Physico - chemical properties of PFR, STTC and condensates (TT1-TT5)

\begin{tabular}{|c|c|c|c|c|c|}
\hline \multirow[b]{2}{*}{ IERs } & \multirow[b]{2}{*}{$\%$ of STTC in IER } & \multicolumn{2}{|c|}{ Density (g/mL) } & \multicolumn{2}{|c|}{ Percentage } \\
\hline & & Wet & Dry & $\begin{array}{l}\text { Gravimetric } \\
\text { swelling }\end{array}$ & Attritional breaking \\
\hline PFR & 0 & 2.12 & 2.02 & 87.42 & 8.52 \\
\hline TT1 & 10 & 1.83 & 1.79 & 77.32 & 9.88 \\
\hline TT2 & 20 & 1.70 & 1.64 & 74.34 & 11.72 \\
\hline TT3 & 30 & 1.64 & 1.60 & 68.55 & 16.33 \\
\hline TT4 & 40 & 1.48 & 1.31 & 52.08 & 20.77 \\
\hline
\end{tabular}




\begin{tabular}{|c|c|c|c|c|c|}
\hline TT5 & 50 & 1.25 & 1.12 & 43.12 & 29.88 \\
\hline STTC & 100 & 1.03 & 0.88 & 39.33 & 44.55 \\
\hline
\end{tabular}

Table 3: Cation exchange capacities of PFR, condensates (TT1-TT5) and STTC for selective metal ions (0.1 M) at $303 \mathrm{~K}$

\begin{tabular}{|c|c|c|c|c|c|c|c|c|}
\hline \multirow{2}{*}{ IERs } & \multirow{2}{*}{$\begin{array}{l}\text { \% of } \\
\text { STTC }\end{array}$} & \multicolumn{7}{|c|}{ Cation exchange capacity $\mathrm{m} \mathrm{mol} / \mathrm{g}$} \\
\hline & & $\mathrm{Ca}^{2+}$ & $\mathbf{M g}^{2+}$ & $\mathbf{Z n}^{2+}$ & $\mathbf{P b}^{2+}$ & $\mathrm{Cu}^{2+}$ & $\mathbf{N a}^{+}$ & $\mathbf{K}^{+}$ \\
\hline PFR & 0 & 1.536 & 1.956 & 1.735 & 1.988 & 1.784 & 1.327 & 1.121 \\
\hline TT1 & 10 & 1.426 & 1.725 & 1.700 & 1.735 & 1.688 & 1.201 & 1.102 \\
\hline TT2 & 20 & 1.388 & 1.600 & 1.674 & 1.667 & 1.601 & 1.185 & 1.000 \\
\hline TT3 & 30 & 1.222 & 1.523 & 1.587 & 1.589 & 1.488 & 1.116 & 0.927 \\
\hline TT4 & 40 & 1.104 & 1.141 & 1.435 & 1.457 & 1.392 & 0.988 & 0.854 \\
\hline TT5 & 50 & 0.991 & 1.198 & 1.299 & 1.264 & 1.183 & 0.884 & 0.765 \\
\hline STTC & 100 & 0.853 & 1.044 & 1.000 & 1.022 & 1.000 & 0.764 & 0.687 \\
\hline
\end{tabular}

Table 4: Chemical effect on CEC of PFR and its condensates for exchange with $0.1 \mathrm{M} \mathrm{Zn}^{2+}$ ions at $303 \mathrm{~K}$

\begin{tabular}{|c|l|l|l|l|l|l|}
\hline \multirow{2}{*}{ Reagents } & \multicolumn{6}{|l|}{ Cation exchange capacity, in mol. g-1 0.1M solution } \\
\cline { 2 - 8 } & PFR & TT1 & TT2 & TT3 & TT4 & TT5 \\
\hline CEC (of untreated) & 1.735 & 1.700 & 1.674 & 1.587 & 1.435 & 1.299 \\
\hline $20 \%(w / v) ~ N a O H$ & 1.561 & 1.534 & 1.421 & 1.322 & 1.188 & 1.000 \\
\hline Benzene & 1.624 & 1.587 & 1.498 & 1.388 & 1.239 & 1.145 \\
\hline $1 \mathrm{M} \mathrm{HCl}$ & 1.612 & 1.565 & 1.475 & 1.392 & 1.245 & 1.267 \\
\hline
\end{tabular}

Table 5: Effect of particle size on CEC of PFR and condensates (TT 3) at 303K

\begin{tabular}{|c|c|c|c|c|}
\hline \multirow{2}{*}{ Sample } & \multirow{2}{*}{ Particle Size } & \multicolumn{3}{|c|}{ Cation exchange capacity ( m. mol.g-1 ) } \\
\hline & & $\mathbf{Z n}^{2+}$ & $\mathbf{M g}^{2+}$ & $\mathbf{P b}^{2+}$ \\
\hline \multirow{4}{*}{ PFR } & $<210$ & 1.661 & 1.821 & 1.855 \\
\hline & $210-300$ & 1.735 & 1.956 & 1.988 \\
\hline & $300-500$ & 1.689 & 1.854 & 1.857 \\
\hline & $>500$ & 1.598 & 1.762 & 1.1 .789 \\
\hline \multirow{4}{*}{ TT 3} & $<210$ & 1.298 & 1.444 & 1.527 \\
\hline & $210-300$ & 1.587 & 1.523 & 1.589 \\
\hline & $300-500$ & 1.454 & 1.500 & 1.547 \\
\hline & $>500$ & 1.381 & 1.483 & 1.511 \\
\hline
\end{tabular}

Table 6: FT-IR spectral data of PFR, condensates TT3 and pure STTC $\left(\bar{v}\right.$ in $\left.\mathbf{c m}^{-1}\right)$

\begin{tabular}{|c|c|c|c|}
\hline Group & PFR & Composites TT3 & Pure STTC \\
\hline $\mathrm{S}=$ O str. & 1051 & 1044 & 1038 \\
\hline $\mathrm{SO}_{2}$ sym. str. & 1152 & 1187 & 1192 \\
\hline $\mathrm{C}-\mathrm{S}$ str. & 608 & 598 & 597 \\
\hline Bonded OH str. & 3396 & 3447 & 3427 \\
\hline
\end{tabular}




\begin{tabular}{|c|c|c|c|}
\hline $\mathrm{CH}_{2}-$ def. & 1488 & 1468 & 1431 \\
\hline $\mathrm{C}-\mathrm{C}$ str. & 1639 & 1603 & 1614 \\
\hline $\mathrm{C}-\mathrm{H}$ def. & 880 & 878 & 888 \\
\hline $\mathrm{C}-\mathrm{C}$ def. & 862 & 844 & 839 \\
\hline $\mathrm{SO}_{2}$ assy. & 1332 & 1327 & 1316 \\
\hline
\end{tabular}

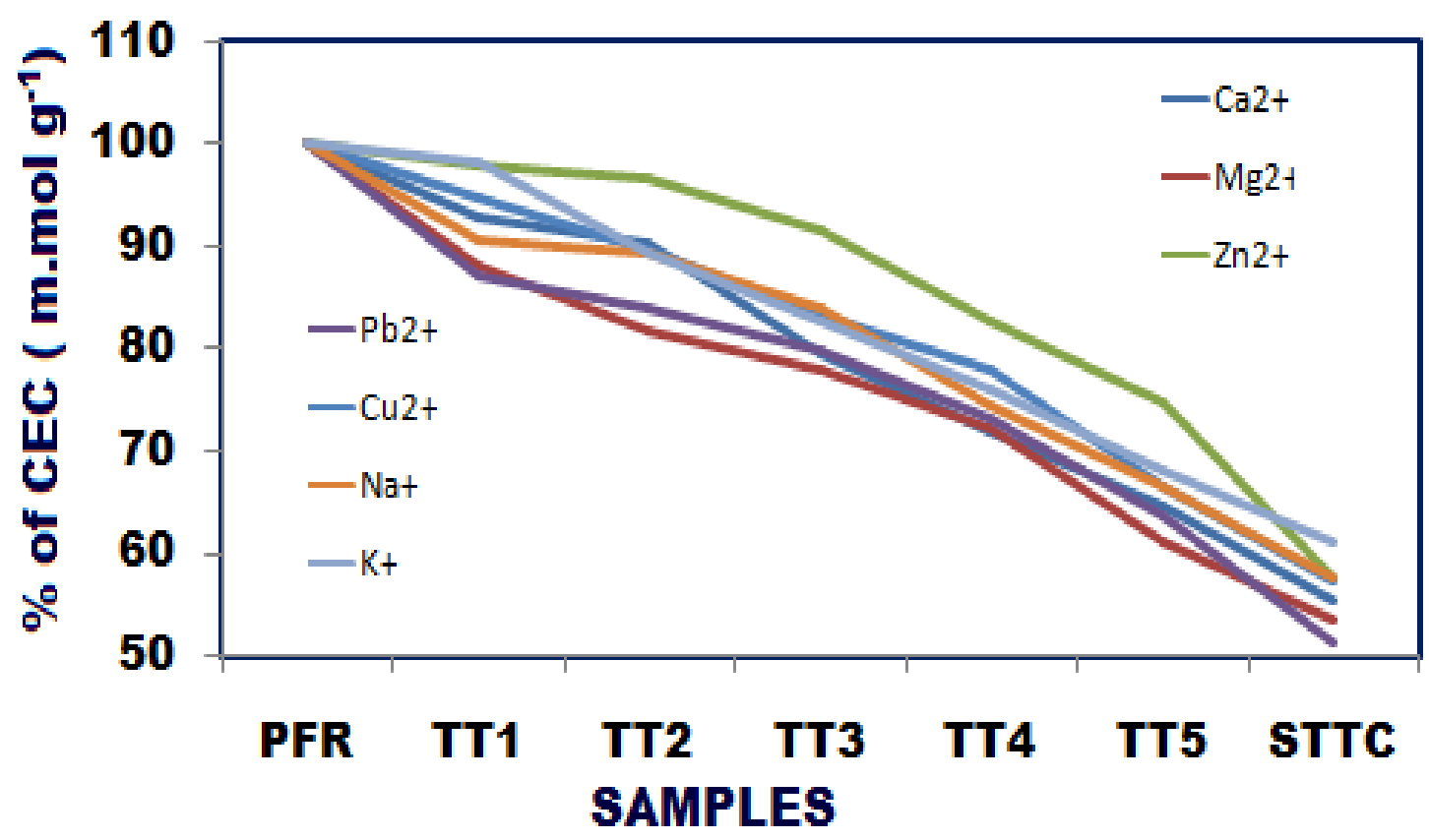

Figure 1: CEC of PFR, TT1-TT5 and STTC for selective metal ions (0.1 M ) at $303 \mathrm{~K}$

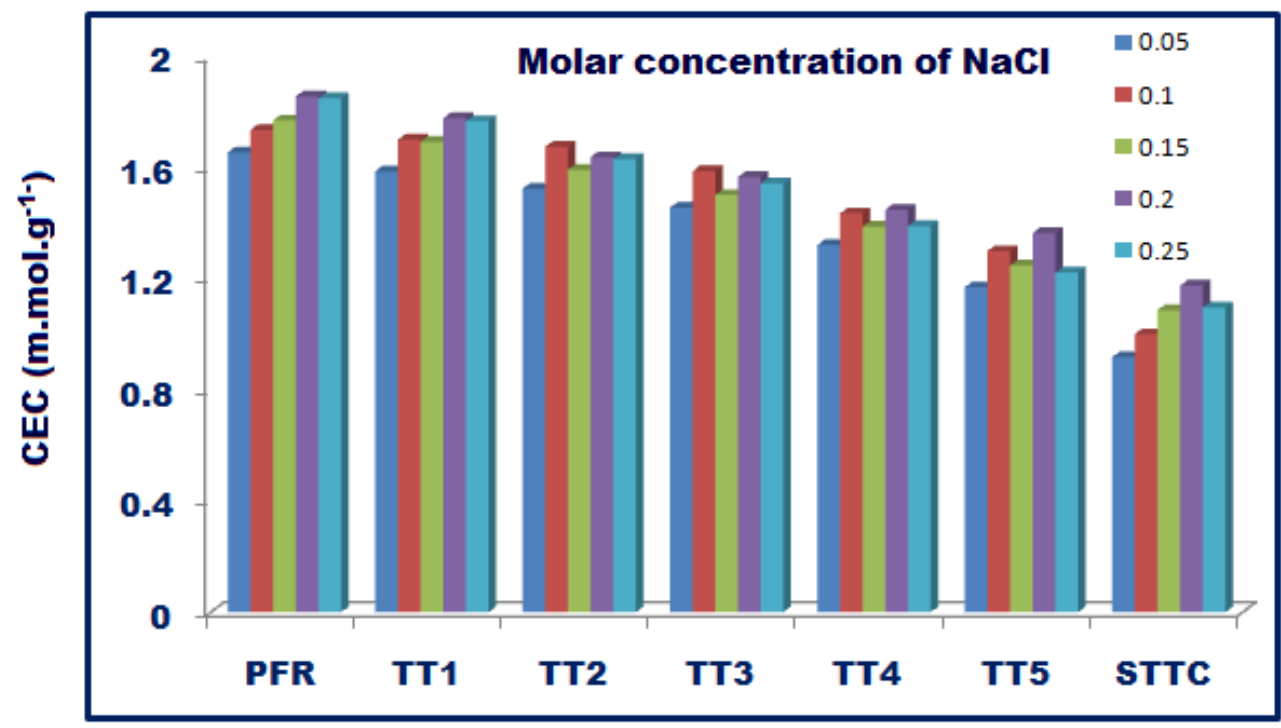

SAMPLES

Figure 2: Regeneration level for PFR, TT1-TT5 and STTC- loaded with $\mathrm{Zn}^{2+}$ ions by using NaCl solution at $303 \mathrm{~K}$. 


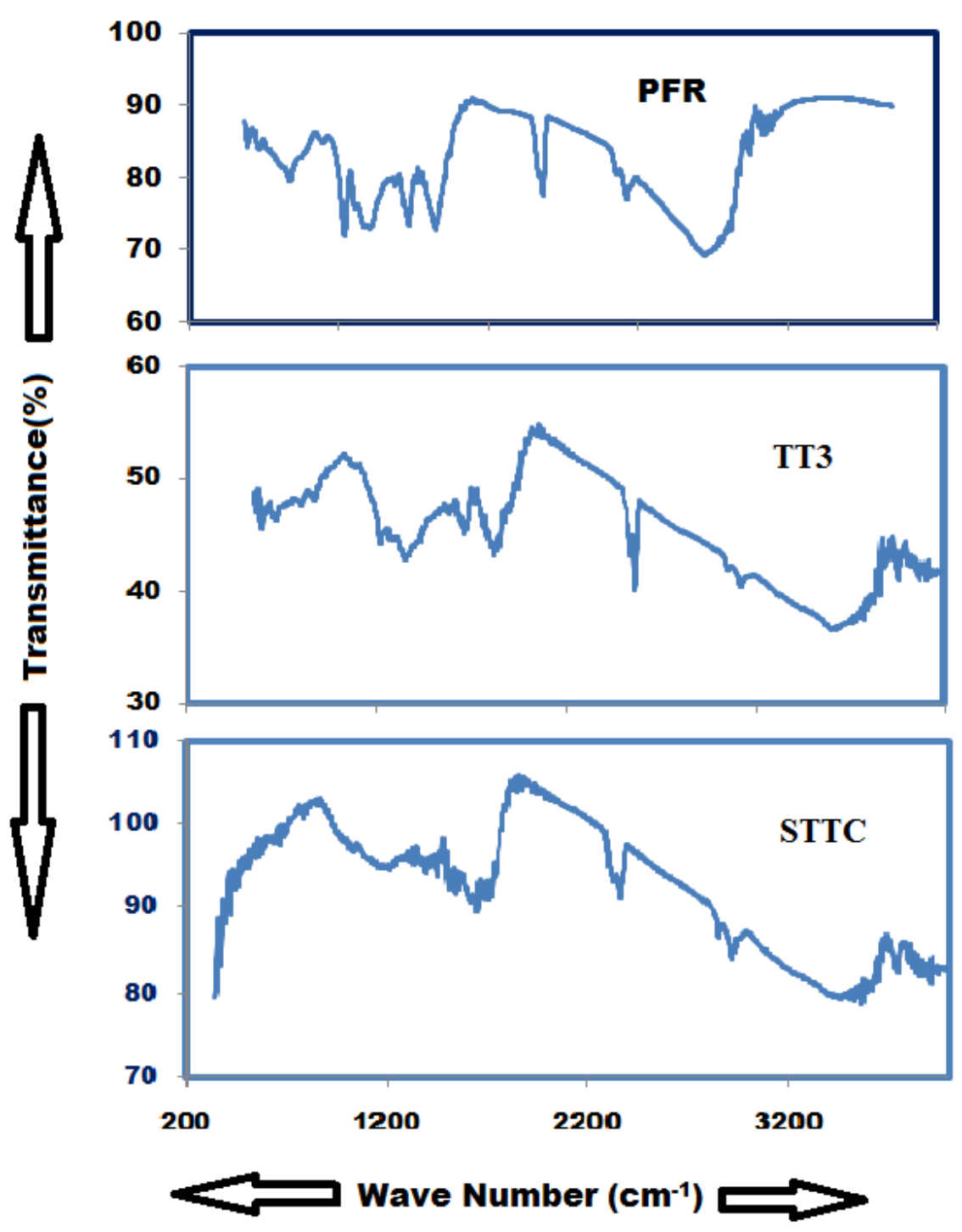

Figure 2: FT-IR spectral of PFR, condensates TT3 and pure STTC $\left(\bar{v}\right.$ in $\left.\mathbf{~ m}^{-1}\right)$ 


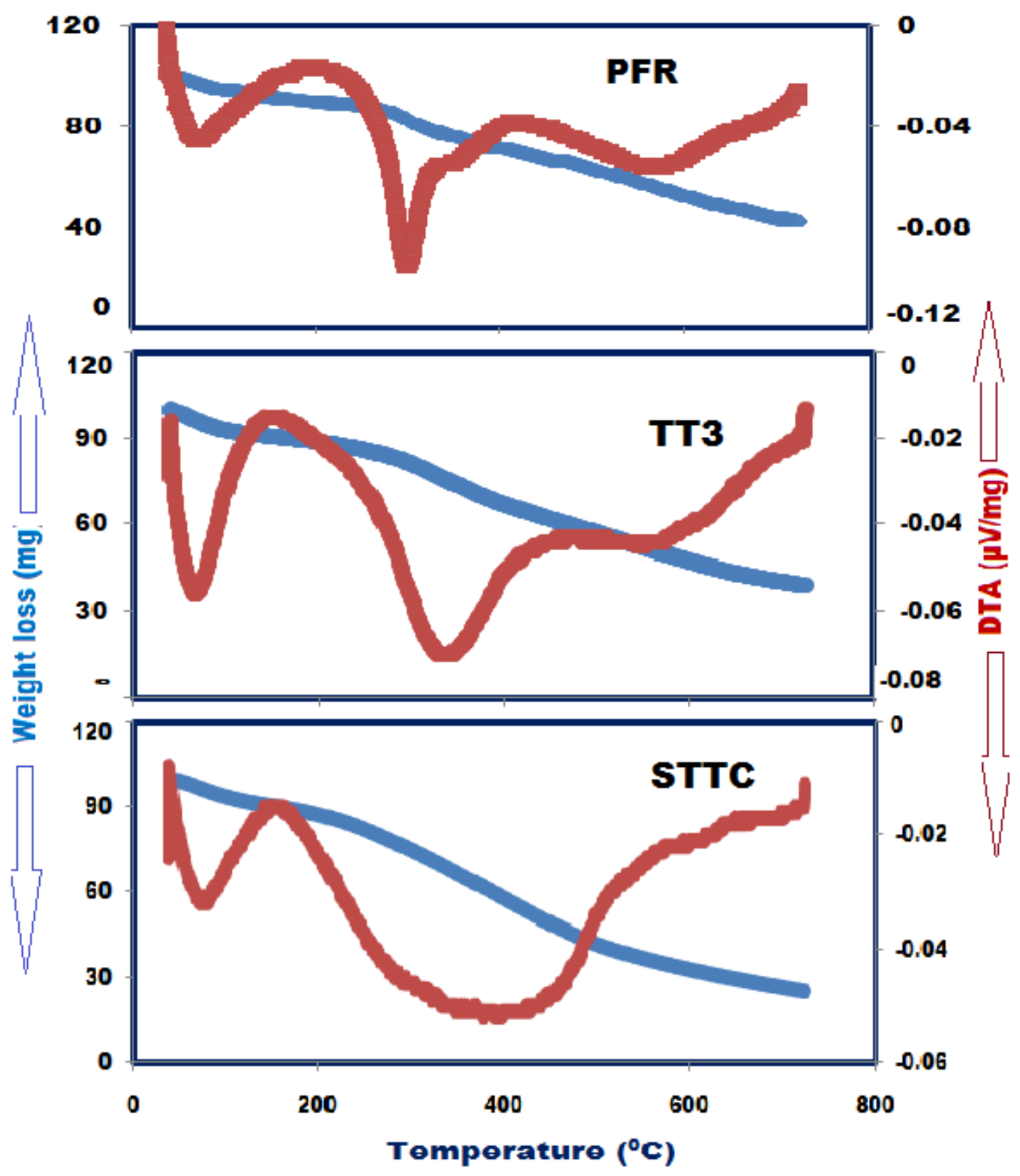

Figure 3: TGA and DTA curves of PFR, condensates TT3 and pure STTC 

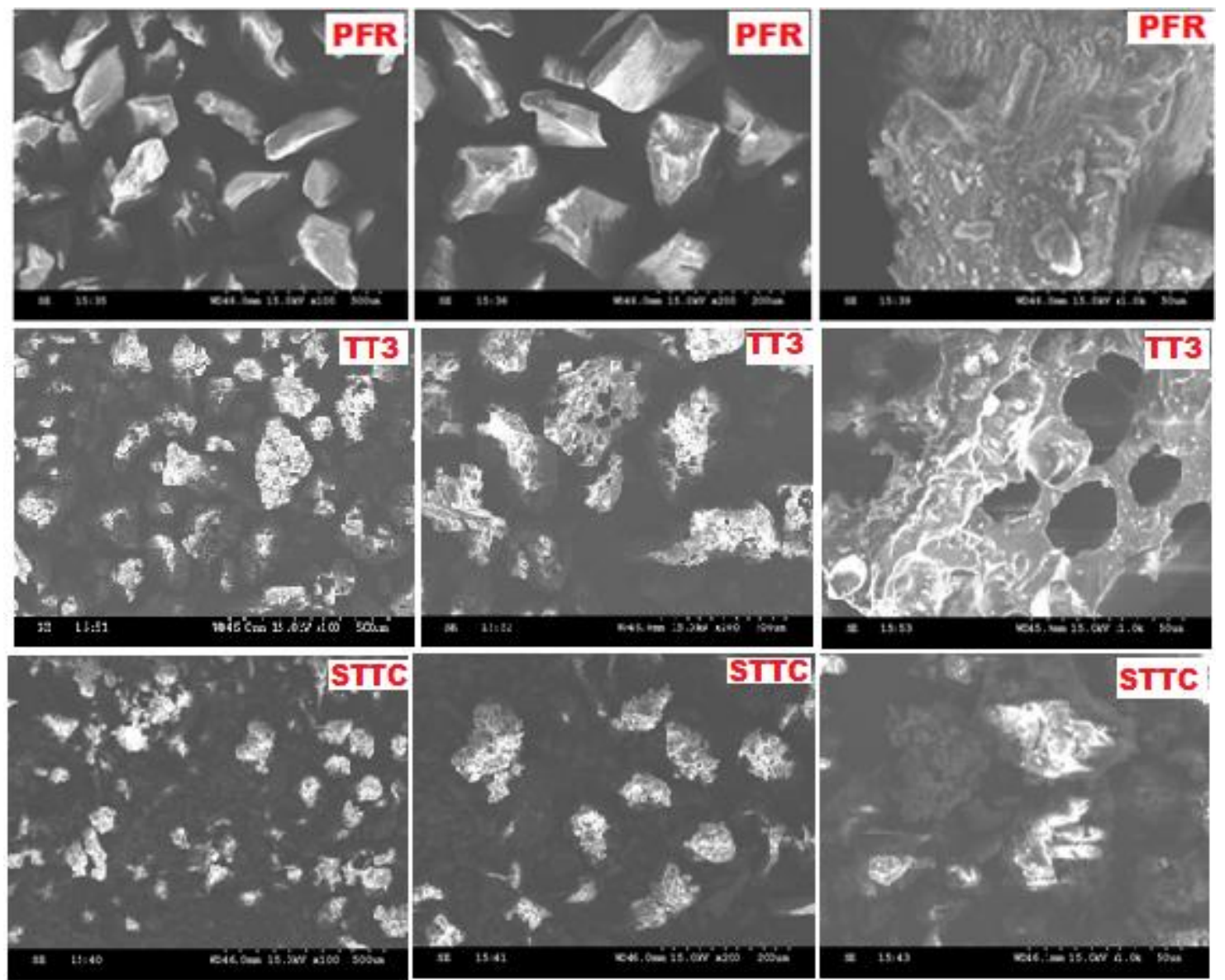

Figure 4: SEM images with different magnification 